\title{
A Undime e os desafios da educação municipal
}

\author{
NEROALDO PONTES DE AZEVEDO
}

"Não é possível refazer este país, democratizá-lo, humanizá-lo,
torná-lo sério, com adolescentes brincando de matar gente,
ofendendo a vida, destruindo o sonho, e inviabilizando o amor.
Se a educação, sozinha, não transforma a sociedade, sem ela,
tampouco, a sociedade muda."

Paulo Freire

\section{Situando a questão}

A CONSTITUIÇÃo FEDERAL, de 1988, e a Lei de Diretrizes e Bases da Educação Nacional, de 1996, definiram com clareza o papel e a importância do município como ente federativo autônomo, na formação e na gestão da política educacional, criando, inclusive, o seu próprio sistema de ensino. Também do ponto de vista legal está definida a colaboração entre União, estados e municípios como sendo o regime adequado para a busca de uma educação de qualidade e não-excludente.

As definições legais têm sido instrumentos necessários para a melhoria do desempenho da educação nos municípios, mas elas só acontecem e têm desdobramentos favoráveis em função do empenho da sociedade organizada e do poder público.

É justo constatar que vem crescendo, hoje, no Brasil, a consciência de que a educação é um direito de todos. Um instrumento fundamental para a construção da democracia brasileira, para a afirmação da nossa cidadania. Multiplicam-se os seminários, os encontros, os prêmios, a divulgação de experiências exitosas, as parcerias, o debate em torno da importância da educação.

Municipalização, financiamento, regime de colaboração são questões centrais no panorama da educação municipal, além de outras, não menos importantes, como formação de professores, avaliação de desempenho, autono-mia das escolas, gestão democrática, projeto político-pedagógico.

Em defesa de uma educação de qualidade, a União Nacional dos Dirigentes Municipais de Educação (UNDime) vem se unindo àqueles que lutam pelo resgate da dignidade da escola pública e atuam em favor da educação. Falar, pois, da 
UNDime, que está completando 15 anos em outubro de 2001, é descrever a ação de um dos agentes dessa luta e, ao mesmo tempo, repassar as principais questões que envolvem a educação pública nos municípios brasileiros, nos últimos anos.

\section{UNDIME: um pouco de história}

Como entidade nacional reunindo dirigentes municipais de educação das diversas regiões do Brasil, a Undime teve seu registro de nascimento em outubro de 1986, quando realizou, no Colégio Militar de Brasília, o seu primeiro fórum nacional.

Mas foi em Pernambuco que a entidade começou a ser gestada, a partir de uma reunião de secretários de educação realizada em agosto de 1985, quase todos pertencentes à região metropolitana do Recife, que "tinham em comum a oposição ao governo estadual e o desejo de realizar uma educação pública transformadora, democrática e de qualidade, apesar das naturais diferenças políticas entre eles" (1).

Fruto dessa articulação, nasceu o $1^{\circ}$ Encontro de Dirigentes Metropolitanos de Educação realizado em Recife, em março de 1986, e, posteriormente, o $1^{\circ}$ Fórum Nacional dos Dirigentes Municipais de Educação, marcando assim a passagem do regional para o nacional do movimento pela educação municipal.

Em tese de doutorado (2), Lúcia Maria Wanderley Neves, explorando os vínculos entre educação e política, analisou o processo de criação da UNDIME, que "se inclui entre as manifestações sociais pela ampliação dos espaços democráticos, a partir da instalação da Nova República". As eleições dão lugar, em Pernambuco, à vitória, na região metropolitana de Recife, a prefeitos oposicionistas, que logo atraem a retaliação por parte do governo do estado.

É, pois, nesse contexto, e em franca contraposição ao Conselho dos Secretários Estaduais de Educação (CONSED) que já havia sido criado em 1982, no Rio de Janeiro, que surge a organização dos secretários municipais de educação. O objetivo explícito do movimento, segundo textos então produzidos pelo Coletivo de Dirigentes Municipais de Educação, era "introduzir a questão da municipalização no debate educacional do país".

A autora analisa a contradição inerente às convergências de interesse entre a UNDIME e o MEC, embora estivessem em posições ideológicas diferenciadas. Controlado pelo PFL, "o MEC, que defendia a tese da municipalização do ensino, viu no apoio a esse movimento nascente uma oportunidade de se legitimar frente às 'áreas fortes' - área econômica, sob o controle do PMDB - da Aliança Democrática”.

Defendendo os interesses maiores da população, o Coletivo de Dirigentes tinha o apoio do MEC, num verdadeiro "emaranhado de interesses contradi- 
tórios", mas lutava pela superação de métodos clientelísticos de administração pública, nos âmbitos federal, estadual e municipal. "Utilizando-se de critérios nem sempre transparentes", comenta Lúcia, "a entrada do MEC no circuito do I Encontro Metropolitano ampliou-o consideravelmente, dando até caráter de política oficial ao que era antes um movimento de grupo que pretendia, de baixo para cima, provocar a mudança de rumo da educação nacional".

Do primeiro Fórum Nacional ao segundo, realizado no final de 87, a entidade consolidou-se nacionalmente, com propostas definidas para a educação: defende a municipalização do ensino, a descentralização dos recursos, a definição de competências das três esferas de ensino. São questões daquela época, são questões de sempre, são questões de hoje.

Presente em todos os estados brasileiros, a Undime, procurando articular e coordenar os interesses comuns das secretarias municipais de educação, legitimouse como instância representativa dos municípios brasileiros, desempenhando papel importante nos processos de discussão, formulação e implementação das políticas nacionais de educação.

\section{Perfil do secretário municipal de educação}

O crescente papel dos municípios na educação infantil, no ensino fundamental e na educação de jovens e adultos tem exigido um perfil diferenciado dos dirigentes municipais de educação, que inclui formação técnica e, ao mesmo tempo, capacidade de formulação e gestão das políticas públicas educacionais.

Em face desse novo cenário da política educacional no país, ficou evidente a necessidade de adoção de mecanismos para a melhoria da gestão municipal da educação. Um dos passos importantes desse processo consiste em conhecer o perfil das pessoas que estão à frente dos órgãos municipais de educação.

Assim, com base no protocolo de cooperação assinado entre a UNESCO e a UnDime, decidiu-se pela realização de uma pesquisa ampla sobre os dirigentes municipais de educação (DME). A pesquisa, publicada no livro intitulado Dirigentes municipais de educação: um perfil (3), foi realizada nos anos de 98 e 99, tendo envolvido 1973 dos 5507 secretários municipais (uma amostragem correspondente a 35\%), por meio de um questionário enviado pelos Correios, abrangendo aspectos como a formação e a qualificação dos DME, a preparação para o cargo, a remuneração dos DME, a filiação partidária, a gestão municipal nas áreas pedagógica e administrativa.

Os resultados da pesquisa revelaram um perfil bastante frágil dos então secretários municipais de educação. Esse perfil, no contexto das aceleradas mudanças a que vem sendo submetida a educação brasileira no atual momento, torna, segundo Palhano, "mais e mais complexa, e conseqüentemente mais difícil, a 
atuação dos DME, na medida que constituem, por razões históricas, um quadro profissional de baixa estruturação interna; comandam órgãos públicos que foram tratados com descaso em quase todos os rincões deste país; dispõem, além disso, de pouca autonomia administrativa, financeira e gerencial.”

Hoje a escolha do secretário municipal de educação a partir de critérios técnicos e a sua inserção em processos de formação continuada é uma exigência para que a administração do ensino público municipal atenda às necessidades da população quanto à escola pública, no que diz respeito à eficiência, à competência, à prática da democracia e da cidadania.

\section{Repensando a municipalização}

Municipalização é termo complexo, revelando diversas facetas e gerando acaloradas discussões. Caberia, de início, fugir à contenda sobre a qualidade - melhor ou pior - da educação ofertada pelos estados ou pelos municípios. A realidade regional é tão diversificada e tão diversa a situação dos estados e dos municípios, que só uma análise aprofundada e específica, revendo a história e apontando tendências, poderia estabelecer parâmetros de comparação.

Há outro tipo de argumentação que pouco elucida o entendimento do problema: uma contraposição entre os que defendem o ensino no município por acreditar que a administração municipal, mais perto do cidadão, é mais democrática e, portanto, mais eficiente, e aqueles que não aceitam a crescente responsabilização do município, particularmente porque tal perspetiva confundese com a orientação neoliberal, presente nos últimos governos, em que a União repassa atribuições para os municípios, isentando-se da sua responsabilidade, tudo em consonância, aliás, com os ditames do FMI e do Banco Mundial. Embora sejam pertinentes os argumentos, analisar a questão só deste ângulo é, no mínimo, uma atitude estática, que não considera as possibilidades de mudança num tal quadro. Há também outros argumentos contrários à municipalização do ensino fundamental, seja porque os municípios são o lugar do "coronelismo", seja porque esgotaram suas possibilidades de atendimento, ou ainda, porque têm menos recursos do que os estados (4). Cabe registrar, mais uma vez, que se as alegações são verdadeiras, elas deixam de contar com a possibilidade, por exemplo, de uma reforma tributária, que possa ser justa para com os municípios. Há ainda, e fortemente, os que não acreditam na capacidade de os municípios fazerem educação de qualidade, porque seus gestores são irresponsáveis com os recursos públicos. Infelizmente é forçoso reconhecer que recursos da educação têm sido, aqui e ali, desviados de sua finalidade. Ao tempo em que é preciso fugir da generalização, é doloroso reconhecer que as falcatruas não são apanágio dos municípios. Acontecem, também infelizmente, nos estados e na União. Só a defesa clara e objetiva de uma marca ética no trato da coisa pública, traduzida pelo acompanhamento sistemático da sociedade civil e pela punição dos culpados, pode mudar tal quadro. 
O fato observado, e digno de acompanhamento, é que vem crescendo o número de alunos no ensino fundamental, sob a responsabilidade dos municípios. Em muitos casos, particularmente depois da criação do Fundo de Manutenção e Desenvolvimento do Ensino Fundamental e de Valorização do Magistério (FUNDEF), o determinante tem sido o financiamento, e não o atendimento ao aluno, do ponto de vista da qualidade do ensino ofertado. Mais de $50 \%$ das matrículas no ensino fundamental, na rede pública, já se concentram nos municípios: essa é a realidade.

Assim, não pode ser vista como benéfica para a educação a municipalização entendida como simples transferência de alunos da rede estadual para a municipal, sem se levar em consideração também os encargos financeiros e a capacidade do município, em cada caso, de ampliar, com qualidade, os seus serviços educacionais.

Em síntese, a municipalização só poderá ser vista como um benefício para a educação se for proveniente de um processo educado de negociação. É forçoso reconhecer que não tem sido essa a prática, na grande maioria dos estados. Ao lutar por uma adequada reforma tributária, ao defender uma nova visão do pacto federativo, marcada pela colaboração, e ao propugnar por um processo de efetiva descentralização, não só dos recursos, mas das decisões, respeitadas as instâncias autônomas, a UNDIME coloca-se a favor de uma educação de qualidade, no âmbito dos municípios brasileiros e do país como um todo.

É feliz a observação do professor José Marcelino: “O que faz boa uma administração pública não é o fato de ser municipal, estadual ou federal, mas o compromisso político de quem a assume" (5).

\section{Financiamento da educação}

É necessário reconhecer que têm acontecido avanços, particularmente no que diz respeito ao ensino fundamental, na busca da universalização e da qualidade. Mas é preciso também reconhecer que os resultados obtidos, recentemente avaliados pelo Sistema de Avaliação da Educação Básica (SAEB), por exemplo, ficam ainda longe daquilo que temos obrigação de almejar. Seria reducionismo atribuir todos os limites à questão do financiamento, sabemos que outros males atingem a educação. Mas, sem dúvida, o atual modelo de financiamento do ensino fundamental, derivado da Emenda Constitucional n. ${ }^{\circ}$ 14, de 27 de setembro de 1996, da Lei n. ${ }^{\circ} 9394$ - Diretrizes e Bases da Educação Nacional - de 20 de dezembro de 1996, e da Lei n. ${ }^{\circ}$ 9424, de 24 de dezembro do mesmo ano, que criou o FUNDEF, passou a definir novos rumos para a educação básica no país.

Responsáveis, legalmente, pelo ensino médio, os estados estão envolvidos em dificuldade, porque vem crescendo o número de matrículas neste nível de ensino, provocado pela melhoria no fluxo de atendimento do ensino fundamental. 
Por sua vez, a educação infantil vem sofrendo prejuízos extraordinários, em conseqüência do afastamento brusco dos estados desta responsabilidade e da necessidade de muitos municípios criarem ou ampliarem as matrículas no ensino fundamental, premidos pela necessidade de recuperarem os recursos retirados compulsoriamente de seus impostos, por força da criação do FUNDEF.

É necessário lembrar que a lei que criou o FUNDEF afastou-se de dois pressupostos que eram defendidos em 1994, quando da mobilização para o Plano Decenal de Educação para Todos: não garantiu um piso nacional de salários e limitou-se ao ensino fundamental. Além disso, três vetos presidenciais trouxeram prejuízos à educação nos estados e particularmente nos municípios. A nãocontabilização do segmento dos jovens e adultos trouxe, até hoje, problemas para essa modalidade de ensino fundamental. A possibilidade de uso, pela União, de recursos do salário educação para a eventual complementação do custo-aluno, diminui o aporte de recursos da União para os Fundos Estaduais. E a não-regimentação da divisão da quota-base do salário educação entre estados e municípios vem gerando, ainda hoje, prejuízos financeiros para os últimos.

Sabe-se que a negociação com os governadores para a aprovação do FUNDEF motivou esse último veto. A UNDime tem lutado pela derrubada dos vetos, mas a correlação de forças lhe tem sido adversa.

Faz-se necessário, com urgência, um aporte de recursos para a educação infantil. Quanto à educação de jovens e adultos, o recém-lançado programa "Recomeço" pretende corrigir uma lacuna. É cedo para avaliação. Cabe assinalar que a implantação do FUNDEF trouxe um impulso novo para a busca da universalização do ensino fundamental e propiciou, particularmente nos municípios pequenos das regiões Norte, Nordeste e Centro-Oeste, melhoria salarial para os professores. Em muitos casos o avanço se deu com a elaboração dos Planos de Carreira e Remuneração do Magistério, incentivando de modo especial a qualificação e a titulação dos profissionais do magistério.

O problema mais grave com relação ao FUNDEF é, sem dúvida, a definição do custo-aluno. Definido em $1997 \mathrm{em} \mathrm{R} 300$ por ano, hoje encontra-se ainda em patamares que ferem a própria legislação: $\mathrm{R} \$ 363$ para a $1^{\mathrm{a}}$ à $4^{\mathrm{a}}$ série, e $\mathrm{R} \$ 381,15$ para a $5^{\mathrm{a}}$ à $8^{\mathrm{a}}$, quando $\mathrm{R} \$ 540$ seria o mínimo, para se cumprir a lei.

Para justificar o desrespeito ao $\$ 1^{\circ}$ do art. $6^{\circ}$ da Lei 9424/96 - “O valor mínimo anual por aluno, ressalvado o disposto no parágrafo $4^{\circ}$ será fixado por ato do Presidente da República e nunca será inferior à razão entre a previsão da receita total para o Fundo e a matrícula total do ensino fundamental no ano anterior, acrescida do total estimado de novas matrículas, observado o disposto no art. $2^{\circ}$, parágrafo $1^{\circ}$, incisos I e II" - o governo federal impõe um entendimento que afronta a própria lei, apresentando uma interpretação intencionalmente equivocada ao tomar como referência índices por estado, e não pelo conjunto do país. 
A eficiente propaganda oficial garantiu, por exemplo, que o FUNDEF se fixasse no imaginário popular, e mesmo no âmbito dos que fazem educação, como o grande financiamento do governo federal para o ensino público. Ressaltese que, para este ano de 2001, a contribuição da União não deverá chegar sequer a $3 \%$ do total de recursos envolvidos no FUNDEF, que é da ordem de cerca de R\$ 19 bilhões. Com isso, não mais do que sete estados deverão receber complementação do governo federal a título do FUNDEF.

Não deixa de ser preocupante que o FUNDEF tem prazo de vigência; muitos municípios terão sua capacidade de investimento reduzida. É importante corrigir os desvios da atual legislação e discutir um novo perfil para o Fundo. Segmentos do Congresso Nacional e da área de educação vêm propondo a criação de um Fundo de Desenvolvimento da Educação Básica (FUNDEB), em substituição ao FUNDEF. O FUNDEB, segundo seus proponentes, viabilizaria a democratização da participação dos estados e dos municípios na oferta de todas as etapas da educação básica; a possibilidade da elevação do custo-aluno-médio-anual; e um maior esforço para a arrecadação fiscal e eficiência da gestão.

O inalienável direito do cidadão a uma educação digna exige a imediata revisão do custo-aluno em valores que, no minimo, respeitem a lei. Essa seria uma das contribuições positivas no processo de aperfeiçoamento do regime de colaboração.

\section{Regime de colaboração}

A Constituição Federal, no seu art. 211, define a organização do sistema educacional no país: “A União, os estados, o Distrito Federal e os municípios organizarão em regime de colaboração seus sistemas de ensino."

A Emenda Constitucional n. ${ }^{\circ} 14$, no seu art. $3^{\circ}$ definiu, de forma objetiva, o papel de cada sistema de ensino, atribuindo responsabilidades específicas, mas consolidando o regime de colaboração.

“Art. $3^{\circ}$ - É dada nova redação aos $\$ \$ S 1^{\circ}$ e $2^{\circ}$ do art. 211 da Constituição Federal e nele são inseridos mais dois parágrafos, passando a ter a seguinte redação:

“Art. $211-$

$\mathfrak{S} 1^{\circ}$ - A União organizará o sistema federal de ensino e dos territórios, financiará as instituições de ensino públicas federais e exercerá, em matéria educacional, função redistributiva e supletiva, de forma a garantir equalização de oportunidades educacionais e padrão mínimo de qualidade do ensino, mediante assistência técnica e financeira aos estados, ao Distrito Federal e aos municípios.

$\$ 2^{\circ}$ - Os municípios atuarão prioritariamente no ensino fundamental e na educação infantil. 
$\$ 3^{\circ}$ - Os estados e o Distrito Federal atuarão prioritariamente no ensino fundamental e médio.

$\$ 4^{\circ}$ - Na organização de seus sistemas de ensino, os estados e os municipios definirão formas de colaboração, de modo a assegurar a universalização do ensino obrigatório."

A Emenda consolidou uma prioridade para o ensino fundamental, dando origem ao FUNDEF, tornando mais graves ainda as obrigações do município, no sentido de universalizar o ensino fundamental.

Só uma reforma tributária que descentralizasse recursos, em função das obrigações, poderia tornar menos penoso para os municípios o exercício, com qualidade, das suas obrigações legais. Como se sabe, tal fato não ocorreu, e a União continua centralizando recursos e, por conseqüência, centralizando decisões.

Era de se esperar que uma efetiva colaboração entre União, estados e municípios, garantida na lei, se traduzisse efetivamente em prática.

A União não vem cumprindo o seu papel, no que diz respeito ao ensino fundamental, porque, conforme já assinalamos, desrespeita a própria legislação que criou o FUNDEF. Se o custo-aluno, hoje, estivesse nos patamares exigidos pela legislação, no mínimo 15 estados da Federação estariam recebendo complementação da União, o que significaria, na prática, um elemento de contribuição para diminuir as desigualdades regionais.

A tarefa supletiva da União ocorre principalmente com os recursos do salário-educação, repassados para estados e municípios mediante convênios geridos pelo Fundo Nacional de Desenvolvimento da Educação (FNDE), de forma descontínua, trazendo dificuldades para o planejamento dos estados e dos municípios.

Uma outra forma de colaboração, com caráter redistributivo, é o Fundescola, antigo Projeto Nordeste, que atua nas regiões Norte, Nordeste e CentroOeste, com significativa parcela de recursos provenientes do Banco Mundial, que dita normas rígidas para os investimentos. Tal forma de atuar é um dos principais fatores de centralização de poder.

A relação entre estados e municípios ainda não atingiu um patamar de colaboração no nível desejado. Ao longo dos anos, presenciou-se a um crescimento diferenciado e, na maioria dos casos, conflitante entre as duas redes. Os estados ainda se comportam com uma atitude de tutela em relação aos municípios, e o relacionamento fica ao sabor das alianças político-partidárias.

Exemplo típico desta concepção equivocada de colaboração é a distribuição dos recursos do salário-educação. Dois terços desses recursos são repassados para os estados, que têm a obrigação de reparti-los com os municípios, e apenas 
11 deles definiram essa forma de distribuição. O fato é que, sendo estados e municípios entes autônomos da federação, não há motivo para se submeter o repasse da quota dos municípios à aprovação da lei nas Assembléias Legislativas. O resultado desse encaminhamento, adotado pela União por pressão dos governadores, é um imenso e desnecessário desgaste para os municípios e, muitas vezes, a retenção daqueles recursos pelos estados, pelo que não sofrem penalidade alguma, ficando esta, para os alunos da rede municipal que também têm assegurado, na Constituição, seu direito à educação. Perdemos a conta de quantas vezes, como Undime, encaminhamos ao MEC reivindicação no sentido de que a União repassasse a quota do salário-educação diretamente aos municípios, sem que nenhuma providência tenha sido adotada para resolver a questão, em que pese as reiteradas manifestações de concordância com o nosso pleito. Uma emenda constitucional apresentada pela UNDIME ao MEC, se votada pelo Congresso Nacional, já teria há muito resolvido a difícil situação. Tem, nossa proposta de emenda, o seguinte teor:

"Incluir os parágrafos $8^{\circ}, 9^{\circ}$ e 10 no art. 60 do Ato das Disposições Constitucionais Transitórias, ou seja:

$\$ 8^{\circ}$ - Os $2 / 3$ dos recursos do salário-educação serão divididos, no âmbito de cada unidade da federação, excluindo-se o Distrito Federal, entre os estados e respectivos municípios, levando-se em conta o número de alunos matriculados, conforme apuração do censo nacional de educação realizado pelo MEC.

$\$ 9^{\circ}$ - Na definição do montante a ser distribuído entre estado e municípios, dar-se-á peso 2 (dois) ao aluno matriculado no ensino fundamental e peso 1 (um) ao aluno matriculado no ensino médio e na educação infantil.

$\$ 10^{\circ}$ - Pelo período de vigência dos fundos de que trata o parágrafo $2^{\circ}$, os estados e o Distrito Federal, bem como os municípios, conforme o definido no parágrafo $8^{\circ}$, poderão utilizar recursos de sua participação na arrecadação da contribuição social referida no parágrafo $5^{\circ}$ do Artigo 212 , para promover a expansão e o desenvolvimento do ensino médio e da educação infantil, desde que não haja prejuízos ao atendimento ao ensino fundamental para a população em idade correspondente."

Por iniciativa da Undime, foi possível constituir um grupo de trabalho com o CONSED, e ficou sistematizado um programa de colaboração entre estados e municípios. No âmbito das duas entidades, este entendimento vem prosperando. A dificuldade se dá na efetivação desses propósitos em cada estado. Os procedimentos equivocados em torno da chamada municipalização, de que já falamos, são provenientes desta falta de espírito de colaboração.

Abre-se, assim, mais um espaço propício para a análise e o encaminhamento do regime de colaboração. Promulgado o Plano Nacional de Educação, o momento 
é de se discutir os Planos Estaduais e os Planos Municipais de Educação. Só uma participação efetiva da sociedade poderá contribuir para que tais procedimentos não consolidem uma disputa, mas uma colaboração.

É preocupante o já acontecido com o PNE. Duas propostas, em disputa no Congresso Nacional, uma proveniente do poder executivo, e outra encaminhada por entidades da sociedade civil, deram lugar a um texto que em muito deve ao que o Brasil hoje precisa para planejar o seu desenvolvimento, tendo a educação como um dos seus pilares. Mais grave, porém, é que nove dispositivos foram vetados pelo presidente da República, responsáveis pela questão do financiamento da educação. Planejar sem prever recursos é transformar o PNE em uma carta de intenções. Abre-se uma verdadeira batalha pela derrubada dos vetos. Difícil, mas possível.

Só uma relação de colaboração, de respeito à autonomia, de divisão de responsabilidades e de consciência do papel da educação pode contribuir para a melhoria do atual quadro de dificuldades da educação do país.

\section{Concluindo}

O relatório de Desenvolvimento Humano de 1999, elaborado pelo Programa das Nações Unidas para o Desenvolvimento (PNUD), aponta que o Brasil tem uma das piores distribuições de riqueza do mundo, inexistindo políticas sociais públicas e integradas que possam garantir a 60 milhões de crianças e adolescentes o direito à vida, à educação, a um convívio familiar sadio, entre outros direitos.

Para garantir os acordos com o Fundo Monetário Internacional, a maior parte dos recursos do país tem sido utilizada para o pagamento das dívidas interna e externa, deixando em plano inferior a dívida social com os milhões de excluídos, não só do mercado de trabalho, como também do acesso aos direitos mínimos do ser humano.

Dados divulgados pelo UNICEF demonstram que, enquanto os gastos com o social e o investimento com crianças caíram, os recursos para o pagamento da dívida pública dobraram no mesmo período: "Os recursos destinados ao atendimento de crianças e adolescentes não foram poupados dos cortes. No período entre 1995 e 1998, o chamado orçamento criança teve um decréscimo de US\$ 2,75 bilhões para US\$ 2 bilhões". Além disso, ainda segundo o UNICEF, os recursos destinados à educação de crianças até seis anos baixaram de US\$ 36 para US\$ 30,3 milhões, enquanto programas de renda mínima sofreram cortes de 80\%”.

Embora limitado, é de se saudar o lançamento, por parte do governo federal, de um programa de renda mínima, do tipo Bolsa-escola. Em fase de implementação, não é possível ainda uma avaliação de seus resultados. 


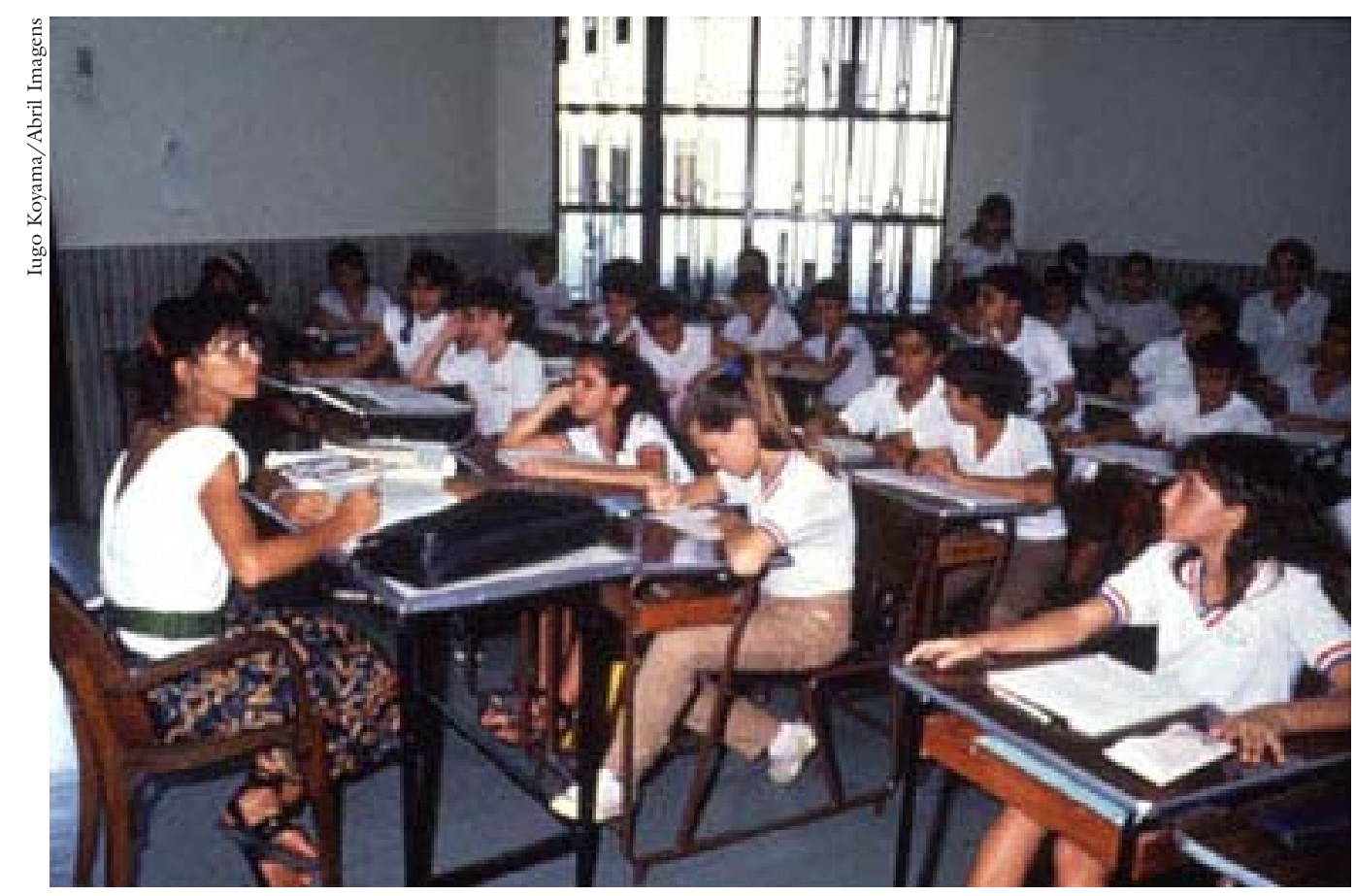

A UNDIME se une àqueles que lutam pelo resgate da dignidade da escola pública e atuam em favor da educação

É auspicioso ver que vem crescendo o interesse da sociedade pela educação e que formas de colaboração cidadãs estão sendo postas em prática pelas Igrejas, pelas empresas, ou por organizações não-governamentais. Também há consciência de que tais formas de colaboração não podem substituir o dever do Estado para com a educação. Embora ainda precária, a participação da sociedade no acompanhamento e no controle dos gastos públicos com a educação é, sem dúvida, fator importante que deve ser incentivado.

A tão propalada prioridade da educação ainda não se traduziu, na prática, em ações que apontem uma perspectiva de mudança real, exigida pelos desafios do século XXI.

Num país tão extenso, tão diferenciado, a UNDIME tem um papel a cumprir: fazer com que os municípios participem do debate nacional sobre educação e, mais ainda, busquem cada vez mais, articulando parcerias, realizar uma educação de qualidade.

\section{Notas}

I Raul Jungmann, que veio a ser o primeiro secretário-executivo da UNDIME, registrou o início das articulações, em nota intitulada Elementos para uma história da UNDIME, publicada em junho de 1988, no número de estréia de Educação Municipal, revista criada pela entidade. 
2 Ver Lúcia Maria Wanderley Neves. A hora e a vez da escola pública. Rio de Janeiro, UFRJ, 1991. Uma síntese da tese deu lugar à publicação Educação e politica no Brasil de hoje, São Paulo, Cortez, 1994.

3 Coordenada por Júlio Jacobo Waiselfisz e analisada por Raimundo Nonato Palhano Silva, a pesquisa foi publicada no ano de 2000 , numa edição da UNESCO, UNDime e Fundação Ford, e encaminhada a todos os prefeitos do país.

4 Ver José Marcelino de Rezende Pinto, Algumas ponderações sobre o debate a respeito da municipalização do ensino fundamental. In: Myriam Krasilchik (org.) USP fala sobre educação. São Paulo, FE-USP, 2000.

5 Id., ibid., p. 78.

Neroaldo Pontes de Azevedo, doutor em Literatura Brasileira pela USP, com a tese publicada Modernismo e regionalismo: os anos $20 \mathrm{em}$ Pernambuco, é atualmente secretário de Educação e Cultura do município de João Pessoa, Paraíba. Foi reitor da Universidade Federal da Paraíba e presidiu a Undime, de abril de 1997 a abril de 2001. 